\title{
Obedience as a function of experimenter competence*
}

\author{
LOUIS A. PENNER $\dagger$, HAROLD L. HAWKINS, MAX C. DERTKE \\ PAUL SPECTOR, and ANTHONY STONE \\ University of South Florida, Tampa, Florida 33620
}

\begin{abstract}
The purpose of this study was to investigate obedience to an E's commands as a function of $E$ competency. Based upon Orne's $(1962,1969)$ discussion of the demand characteristics inherent in the typical aggression study, it was hypothesized that $\mathrm{E}$ incompetence would decrease $\mathrm{S}$ obedience. Competence was manipulated by: (1) presenting some Ss with a nervous and inexperienced E, and (2) "accidentally" killing the victim (a rat) midway through the experiment. Thirty-two undergraduate female Ss participated in the experiment-supposedly a study on the physiological effects of stress. Obedience was operationalized as the difference, in simple reaction time, between trials on which Ss were told that their response might result in shock to the rat and trials on which they were told that their response might save the rat from shock. Significant differences in obedience were obtained between competent and incompetent E conditions, and a significant "kill" effect was found in the competent E condition. The results of this study suggested that the extreme acts of obedience observed in the laboratory (e.g., Milgram, 1963) occur only when E is perceived as competent. This finding imposes limits on the generalizability of laboratory studies of obedience.
\end{abstract}

In a now classic series of experiments, Milgram (1963, 1965) has observed that normal adult Ss, performing under laboratory conditions, can be induced by an $\mathrm{E}$ to administer electric shock to another human being at intensity levels well in excess of those clearly designated as dangerous. Further examples of such seemingly callous and destructive interpersonal behavior have been reported in laboratory studies by Young (1952), Buss (1961), and Orne and Evans (1965).

The apparent ease with which such antisocial behavior patterns can be elicited under varying laboratory conditions has suggested to Milgram, among others, that they reflect a most unfortunate, but nevertheless fundamental, quality of man's nature. Orne (1962, 1969; Orne \& Evans, 1965; Orne \& Holland, 1968) has offered a more optimistic interpretation of Milgram's findings which is based on the view that the psychological laboratory may not, in these cases, constitute a satisfactory analogue to the nonexperimental world outside. The S's performance in a laboratory experiment, Orne has reasoned, is governed by his perception that the experiment is a legitimate endeavor conducted by a responsible scientist-experimenter who represents a larger society that will not condone a research activity contrining any genuine risk to the health and safety of its participants. The alleged situation confronting the $\mathrm{S}$ in Milgram-type studies of compliance is clearly incongruous with this set. The $S$ is likely to resolve this incongruity by assuming he has been deceived and that the "victim" is not in fact in real danger. Accordingly, S's compliance

*This research was supported in part by a grant from the Office of Sponsored Research, University of South Florida.

$\dagger$ Requests for reprints should be sent to Louis A. Penner, Department of Psychology, University of South Florida, Tampa, Florida 33620. may not reflect a genuine willingness to inflict serious harm on another individual, but rather a desire to be a "good" $S$ by collaborating in the deception with the $\mathrm{E}$ who is to be trusted to assume full responsibility for the safety of all participants. Orne's argument, in short, is that the deceptions around which the studies of obedience have been built are likely to seem implausible to $S$ because of his belief that no real harm to a human victim will be tolerated in the experimental setting. The present study attempted to deal with Orne's criticism. Shock levels were ostensibly high (apparently lethal, in fact), but white rats rather than human beings were used as victims. This procedure has several appealing features. Genuinely painful levels of shock can be administered to rat victims, and the rat's reaction to such shock will unequivocally demonstrate the reality of the situation to Ss. In addition, pilot work conducted prior to the present research indicated that many college students find the task of shocking a white rat about as noxious as that of shocking a human. Whether this result was due to differences in believability or to a discrimination failure is of no immediate consequence. What is important, for present purposes, is that $S$ s can be expected to react negatively to orders to inflict pain on a white rat.

The major purpose of the present study was to assess the effects of two manipulations which might be expected to influence a S's willingness to comply with orders to inflict pain on another organism. Under one condition of the study, E exhibited a normal degree of competence and, under a second condition, a moderate degree of incompetence. As Orne (1969) has pointed out, $S$ 's abdication of responsibility may be based in part on the tacit assumption that $\mathrm{E}$ will control the experimental situation and therefore will assume full responsibility for the consequences of the behaviors demanded of $\mathrm{S}$. If $\mathrm{E}$ exhibits a significant degree of incompetence and irresponsibility, it might be expected 
that the $\mathrm{S}$ will react by assuming a greater share of the responsibility for his own actions and hence show less compliance. All Ss were told that painful shock levels would be used throughout the experiment. Midway through the experimental session, at both levels of $E$ competence, the victim was "accidentally" given what appeared to be a lethal dose of shock. [In fact, the rat was given electroconvulsive shock (ECS) of sufficient magnitude to reliably induce a grande mal seizure.] This procedure constituted the second experimental manipulation. It was expected that the apparent death of the victim would alter S's judgments of the extent of the danger faced by victims and that this, in turn, would produce a decline in compliance.

The general procedure (Penner \& Hawkins, 1971) was as follows. Prior to each trial of the experiment, each $S$ was informed that she was either a "harmer" or a "saver." A trial was initiated by the onset of a stimulus light to which all Ss were instructed to quickly respond (Donder's Type a reaction). The Ss were instructed further that if an individual designated the harmer were faster to respond on a given trial. the victim would be shocked. If, however, a saver were faster, then no shock would be administered. The Ss were explicitly ordered to respond as quickly as possible on all trials regardless of their designation. Compliance was defined in terms of the degree of adherence to the instruction to respond as rapidly as possible on both saving and harming trials. The larger the reaction time difference between harming and saving trials, the less the measured compliance.

\section{METHOD}

\section{Design}

A 2 by 2 by 2 factorial design, with two between- and one within-S variable, was used. The $E$ (either E 1 or $E 2$ ) and his manner (either "competent" or "incompetent") were the between-S variables and trials, specifically, the first 20 vs the last 20 of a 40 -trial series was the within-S variable. A supposedly unintended "kill" (the delivery of ECS instead of footshock) occurred on the 20 th trial of the series.

\section{Subjects}

Thirty-two female undergraduate psychology students served as volunteer Ss in the experiment. Students received extra credit grade points for participation in the study.

\section{Apparatus}

Each $S$ was seated at one of four partitioned booths containing a stimulus display-response panel visible only to the $S$ seated at that booth. The display-response panels each contained (1) a RT stimulus light. (2) a RT response button, and (3) four numbered lights, corresponding to the four numbered booths which served to inform each $S$ as to whether she would be a harmer or a saver on a given trial. The $\mathrm{S}$ booths also contained three electrode leads for the supposed measurement of physiological "reactions." An operant rat chamber was located on a raised platform approximately $3 \mathrm{ft}$ from the Ss. The rat chamber was equipped with clear Plexiglas sides, a grid floor, and associated cables for the delivery of both footshock and ECS. Cables from the Skinner box. display-response panels, and physiological electrodes led to the 1 " "itation." located hehind a partition in the same room as $S s^{\prime}$ bouths.

At this station were four standard alectric timers. connced to the four RT response buttons and electromechanical witches. connected to the RT stimulus light and the four numbered ingnal lights on the display-response panels. Also, this focation contained the shock generator and scrambler. used to provide footshock to the grid floor of the operant chamber, and a separate shock generator for the ICS. delivered to the rat through electrodes attached to the rat's ears.

Rats used in the study were fenale albinos of the lisher strain, approximately 100 days old. They wore a leather harness. used to support the ECS electrodes, and were "gentled" and adapted to the LCS harness and operant chamber prior to datal collection.

\section{Procedure}

One to two weeks prior to the start of group data colkction. all Ss were administered Rokeach's (1960) dogmatism scalc and the Adorno et al (1950) "F" scale-supposedly as a part of another experiment. Following completion of these tests. Ss were asked to fill out time-availability forms for another experiment being conducted by "two other students." Ss were selected for inclusion in this study on the basis of times available without regard to their performance on either of the scales. Ss were scheduled for the study and notitied by letter.

The Ss, in groups of four, were assigned randomly to onc of the two competency conditions (i.e.. incompetent or competent) conducted by one of the two Es. The Es conducted equal numbers of sessions under each condition of $E$ competence. Both Es were male Caucasians in their early 20s. During each experimental session. the $E$ was assisted by another male Caucasian who was seen only briefly by Ss.

All Ss were told by tape-recorded instructions that the experiment was a study of physiological and psychological reactions to a particular stress situation. specifically, the shocking of a laboratory animal. The recorded instructions explained the function of the physiological recording equipment and directed that each of the four Ss would have the opportunity to administer shocks on some trials (as "harmers") and to prevent the rat from being shocked on other trials (as "savers"). It was explained that on a given trial, the rat would be shocked only if a harmer pushed her RT button before a saver pushed hers and that harmer and saver designations would be communicated by the numbered lights on their response-display panels. The instructions further emphasized that all Ss. regardless of harmer-saver designation, were to respond as quickly as possible on all trials.

Following these instructions, Ss were given five practice trials. with the rat in the Skinner box but with no shock administered. in pressing the RT button when the RT light was illuminated. After practice trials, the 40 actual trials were conducted. On $50 \%$ of the trials, all Ss received information that they were the harmer, i.e., Light 1 was illuminated on S 1's panel, Light 2 on S 2's panel, etc. The rat was actually footshocked (by E's assistant) on $30 \%$ of all trials with mild $(.5-\mathrm{mA})$ scrambled shock delivered through the grid floor of the chamber. This level of shock reliably produced reactions from the rat. On the 20 th trial (on which all Ss were designated as harmers), ECS was delivered along with footshock. The ECS produced convulsions and unconsciousness; a new animal was substituted for the last 20 trials. Debriefing followed the completion of trials.

\section{Competent Procedure}

The procedure outlined above was followed exactly, and E's performance was designed to communicate competence in handling the experiment. He wore a white laboratory coat and behaved in an efficient. self-assured manner. On the 20 th trial. when the rat was "killed." he reacted somewhat matter-of-factly 
Table 1

Reaction Time Differences Between Harming and Saving RTs (in Seconds) as a Function of Competency Condition, Trial Block, and Experimenter

\begin{tabular}{|c|c|c|c|c|c|c|c|c|c|c|c|c|}
\hline & \multicolumn{6}{|c|}{ Competent Experimenter } & \multicolumn{6}{|c|}{ Incompetent Experimenter } \\
\hline & \multicolumn{3}{|c|}{ Trials $1-20$} & \multicolumn{3}{|c|}{ Trials $21-40$} & \multicolumn{3}{|c|}{ Trials $1-20$} & \multicolumn{3}{|c|}{ Trials $21-40$} \\
\hline & $E_{1}^{*}$ & $\mathrm{E}_{2}^{*}$ & Total & $E_{1}^{*}$ & $\mathrm{E}_{2} *$ & Total & $E_{1}^{*}$ & $\mathrm{E}_{2}^{*}$ & Total & $\mathrm{E}_{1}^{*}$ & $\mathrm{E}_{2}^{*}$ & Total \\
\hline $\begin{array}{l}\text { Number Above } \\
\text { Grand Median }\end{array}$ & 1 & 1 & 2 & 4 & 5 & 9 & 6 & 5 & 11 & 6 & 4 & 10 \\
\hline $\begin{array}{l}\text { Median RT } \\
\text { Mean RT } \\
\text { Variance }\end{array}$ & $\begin{array}{l}.076 \\
.161 \\
.075\end{array}$ & $\begin{array}{l}.029 \\
.039 \\
.005\end{array}$ & $\begin{array}{l}.035 \\
.100 \\
.041\end{array}$ & $\begin{array}{l}.128 \\
.373 \\
.493\end{array}$ & $\begin{array}{l}.143 \\
.199 \\
.069\end{array}$ & $\begin{array}{l}.143 \\
.286 \\
.305\end{array}$ & $\begin{array}{l}.177 \\
.581 \\
.779\end{array}$ & $\begin{array}{l}.105 \\
.295 \\
.092\end{array}$ & $\begin{array}{l}.171 \\
.581 \\
.429\end{array}$ & $\begin{array}{l}.265 \\
.708 \\
.685\end{array}$ & $\begin{array}{l}.343 \\
.584 \\
.841\end{array}$ & $\begin{array}{l}.266 \\
.646 \\
.719\end{array}$ \\
\hline
\end{tabular}

and had his assistant take the "dead" rat to the animal colony room while he prepared another animal for the apparatus. When the assistant returned, the last 20 trials were conducted with the new animal

\section{Incompetent Procedure}

In this condition, $\mathrm{E}$ behaved in a manner designed to communicate incompetence and lack of experience. Among other behaviors, he (1) was late in starting the experiment, (2) did not provide an adequate number of chairs in the room for Ss, (3) had a list of incorrect names for the four Ss, (4) simulated a great deal of difficulty running the tape recorder, (5) confused the initial practice trials by failing to have the RT light lit, (6) explained these difficulties by saying to the Ss, "You'll have to excuse me if I seem nervous, but this is only the second time I've done this," (7) played taped instructions that were unfamiliar to the $E$, and (8) on Trial 20 (when the rat was "killed"), became quite upset, saying, "This has never happened before, I don't know exactly what to do," and sent his assistant from the room to seek help from Dr. Penner. The assistant returned reporting that he "couldn't find anyone." The E substituted a new animal, explaining that this was what he guessed he was "supposed" to do.

\section{RESULTS}

Reaction time data for each $\mathrm{S}$ on harming and saving trials was combined to produce two difference scores. These difference scores were arrived at by subtracting saving RTs from harming RTs for the first 20 trials and the second 20 trials. The arithmetic mean and median difference scores for each condition of the experiment are presented in Table 1.

Table 1 also shows marked heterogeneity of variance in the raw score distributions of RT difference scores. A variety of transformations were applied to the raw scores in an attempt to make the data amenable to traditional parametric procedures without success. Accordingly, a nonparametric analogue of the ANOVA procedure was performed on the data presented in Table 1 (Wilson, 1956). Wilson's test permits analysis of main effects and interactions ordinarily tested by factorial parametric techniques. The analysis indicated that the effects of competency $\left(\chi^{2}=6.25\right.$, df $\left.=1, p<.05\right)$ and the Competency by Trials interaction $\left(\chi^{2}=4.00, \mathrm{df}=1\right.$, $p<.05)$ were statistically reliable. Differences were not found between Es for trial blocks or for any other interactions.
The effect attributable to competency of the $E$ is clearly shown in Table 1. Both Es produced RT difference scores of greater magnitude when they behaved in an incompetent rather than a competent manner. Additionally, although a main effect for trials was not obtained, Table 1 shows that latencies for harming trials increased relative to saving trial latencies following the supposed "kill" on Trial 20 in every condition of the experiment. The Competency by Trials interaction obtained in the Wilson analysis is shown, by Table 1, to be due to changes within the competent condition, i.e., both rate of change in RT differences and number of $S s$ who change relative to the overall median RT difference score are greater for the competent condition. McNemar's (1955) test for the significance of change for two related samples was performed on the difference scores for the competent condition (first 20 trials vs second 20 trials), and a significant chi square was found $\left(\chi^{2}=5.06, \mathrm{df}=1, \mathrm{p}<.05\right)$. No comparable effect was found for the incompetent condition.

Scores for the dogmatism and $\mathrm{F}$ scales were found to be uncorrelated with individual RT difference scores. This result is in contrast to the work of Elms and Milgram (1966), who did obtain reliable correlations between their measure of obedience and $F$ scale scores. We note, however, that though statistically significant relationships were not obtained, the results were in the direction expected on the basis of Elms and Milgram's finding-that, in general, high F or D scores were achieved by Ss with relatively low RT difference scores.

The debriefing sessions produced information that none of the $32 \mathrm{Ss}$ had indications regarding the true purpose of the experiment. No Ss were aware of the fact that they were all harmers at the same time or that incompetent behavior was being simulated in the incompetent condition of the study. Most Ss expressed concern about the condition of the animal which was supposedly "killed" midway through the study.

\section{DISCUSSION}

The results of this study provided fairly straightforward support of the hypothesis that the obedience usually observed in the "Milgram" situation 
is. to a large degree, a function of the explicit and implicit guarantees that nothing can really "go wrong." When these guarantees were attenuated either by (a) E's lack of competency or (b) the victim apparently being killed, disobedience (operationalized in this study as the difference between harming and saving RTs) increased rather dramatically. It should be noted that these effects were obtained although the "victim" in the present study was a white rat.

While the results supported this hypothesis, there are certain points which merit further discussion. The first of these relates to why a significant "kill" effect was found only in the competent $\mathrm{E}$ condition. One possible explanation is that there was a simple practice effect operative, for some reason, only in the competent $\mathrm{E}$ condition. In order to test for this possible confound, a control study was run. In the control study, a competent E was used but the rat was not "killed." Rather, a new rat was merely substituted following Trial 20 . No significant trials effect was found $\left(\chi^{2}=.50, \mathrm{df}=1\right.$, $\mathrm{p}>.5$ ).

A more tenable explanation lies in (1) the amount of control the $E$ exerted for the first 20 trials in the competent condition and (2) S's expectations prior to the "kill" trial in the competent condition. The first 20 trials in the competent condition were similar to other studies of aggressive behavior (e.g., Buss, 1961) in that the orders of the E. were explicit and straightforward, viz, to respond as quickly as possible on all trials. There were apparently no variables operative that mitigate this control. However, the rat's apparent death on the 20th trial (a totally unexpected event) served to subvert the previously unchallenged control or authority of the $E$. This resulted in increased latencies on the following harming trials. (The increased difference scores were due almost entirely to increased harming trial RTs.) In addition to the loss of control, there was an element of surprise following the rat's "death." It seems reasonable to propose that $\mathrm{Ss}$ in the competent $\mathrm{E}$ condition were a good deal more surprised by the killing of the rat than were $\mathrm{Ss}$ in the incompetent $\mathrm{E}$ condition. Thus, their behavior changed much more dramatically.

Not only did the incompetent $E$ and the "killing" of the rat yield longer latencies on harming trials, but it also caused increased inter-S variance. (This increased inter-S variance under certain of the postkill conditions forced the usage of a nonparametric statistical technique.) Why did these conditions engender so much variance?

The postexperimental interviews provided at least a partial explanation of the increased variances and informative data about the $S$ 's perceptions, and interpretations, of the E's behavior. Ss under the competent and incompetent conditions understood the instructions equally well, and the latter were neither frustrated nor angered by E's incompetence. However, they did consistently describe the incompetent E's behavior quite differently than the competent E's behavior. The two most common descriptions were that the $\mathrm{E}$ was extremely nervous and/or "did not know what he was doing." Their response to this behavior can perhaps best be described as one of confusion. Specifically. Ss reported a confusing conflict between their expectations as to how an $\mathrm{E}$ was supposed to act and the objectively incompetent behavior they had observed. This may have resulted in E's losing control over Ss. Thus, Ss might have started adopting various "response strategies," which diverged from that implied by E's order to respond as quickly as possible on all trials. The strategy an individual $\mathrm{S}$ adopted seemed to be determined by what was appropriate for her rather than by how E wanted her to respond. These different "response strategies" were not systematically related to the personality variables measured in this study.

While the major finding of this study-that disobedience increases as a function of $E$ incompetence-is not particuarly surprising, it does speak to the question of the conditions under which obedience will or will not occur. There is little doubt that within the normal laboratory setting, Milgram's results can be replicated. However, when the implicit guarantees that accompany the normal laboratory setting are removed (via $E$ incompetence or actual injury to the victim), obedience declines markedly. There seem to be two interrelated reasons for this decline. First of all, an incompetent $E$ lacks the "expert social power" (A's ability to control B's behavior is based on A's expertise; French \& Raven, 1959) normally attributed to a competent E. Thus, Ss are less likely to follow his orders. Second, since E "doesn't know what he is doing," as reported by our Ss, it is harder for S to shift the responsibility for the victim's fate to the E. As Latané and Darley (1970) have shown, such a situation will impel Ss to action-in this case, disobeying $\mathrm{E}$.

Thus, while it does not seem that Milgram's results are a product of demand characteristics as Orne and Holland (1968) have suggested, they are obtainable only under a restricted range of situations. Our results, then, suggest that Milgram's findings can be applied only to those situations where there is little ambiguity concerning the competence of the individual giving orders to aggress.

\section{REFERENCES}

Adorno, T. W., Frenkel-Brunswick, E., Levinson, D. J., \& Sanford, R. N. The authoritarian personality. New York: Harper \& Row, 1950

Baron, R. A. Magnitude of victim pain cues and level of prior anger arousal as determinants of adult aggressive behavior. Journal of Personality \& Social Psychology, 1971, 17, 236-243.

Buss, A. H. The psychology of aggression. New York: Wiley, 1961.

Elms, A. C., \& Milgram, S. Personality characteristics associated with obedience and defiance toward authoritative command. Journal of Experimental Research in Personality, 1966, 1, 282-289. 
French, J. R. P., Jr., \& Raven, B. H. The bases of social power. In D. Cartwright (Ed.), Studies in social power. Ann Arbor Institute for Social Research, 1959, 150-167.

Latané, B., \& Darley, J. M. The unresponsive bystander: Why doesn't he help? New York: Appleton-Century-Crofts, 1970.

McNemar, Q. Psychological statistics. New York: Wiley, 1955.

Milgram, S. Behavioral study of obedience. Journal of Abnormal \& Social Psychology, 1963, 67, 371-378.

Milgram, S. Some conditions of obedience and disobedience to authority. Human Relations, 1965, 18, 57-76.

Orne, M. T. On the social psychology of the psychological experiment: With particular reference to demand characteristics and their implications. American Psychologist, 1962. 17, 776-783.

Orne, M. T. Demand characteristics and quasi-controls. In R. Rosenthal and R. Rosnow (Eds.), Arrifact in behavioral research. New York: Academic Press, 1969.

Orne, M. T., \& Evans, F. J. Social control in the psychological experiment: Antisocial behavior and hypnosis. Journal of Personality \& Social Psychology, 1965, 1, 189-200.

Orne, M. T., \& Holland, C. H. On the ecological validity of laboratory deceptions. International Journal of Psychiatry, $1968,6,282-293$.

Penner, L. A., \& Hawkins, H. L. The effects of visual contact and aggressor identification on interpersonal aggression. Psychonomic Science, 1971, 24, 261-263.

Rokeach, M. The open and closed mind. New York: Basic Books, 1960

Wilson, K. G. A distribution free test of analysis of variance hypotheses. Psychological Bulletin, 1956, 56, 96-101.

Young, P. C. Antisocial uses of hypnosis. In L. M. LeCron (Ed.), Experimental hypnosis. New York: Macmillan, 1952. Pp. 376-409.

(Received for publication January 22, 1973; accepted January 29, 1973.) 